\title{
Recuperación de pequeñas y medianas empresas en concurso a través de sociedades cooperativas y su contribución a la «responsabilidad social concursal»
}

\author{
Carmen Pastor Sempere* \\ Profesora Titular de Derecho Mercantil. Universidad de Alicante. \\ Investigador permanente de la Escuela de Estudios Cooperativos de la Universidad \\ Complutense de Madrid (http://www.ucm.es/info/eec/). \\ Miembro del grupo asesores IUSDECOOP asesores (http://www.uv.es/iudescoop/). \\ Miembro del grupo investigador COMMENDA (www.commenda.es). \\ Árbitro de la Corte de Arbitraje de Sociedades Cooperativas de la Comunidad Valenciana
}

Sumario: I. Introducción. II. Finalidad del procedimiento concursal. III. Fase de convenio: especial referencia a los convenios de «continuación». IV. A modo de conclusión. V. Bibliografía.

Resumen: Resulta altamente preocupante como en un país como España cuyo tejido empresarial se compone de PYMES en niveles muy superiores al de otros países, las medidas de reestructuración empresarial y saneamiento nunca son diseñadas por el legislador pensando en estas PYMES; al contrario, incluso las de tamaño medio acaban «muriendo a lo largo» del procedimiento concursal, abocándolas a una irremediable liquidación. Ante este problema no resuelto por el legislador y una recesión económica que no tiene fin, las sociedades cooperativas están llamadas a desarrollar un papel activo como protagonistas de procesos de reestructuración y recuperación empresarial. Para ello, contamos con la experiencia de nuestra ya vieja reconversión industrial y con la de países, como la República de Argentina, donde la recesión dio lugar al nacimiento de fenómenos sociales espontáneos en los que los trabajadores han protagonizado un movimiento de resistencia económica, conocido como «Movimiento Nacional de Fábricas Recuperadas» caracterizado en la mayoría de las ocasiones, por ser los trabajadores quienes lograron comprar las instalaciones de la empresa concursada y continuaron la explotación a través de una sociedad cooperativa. En este breve trabajo se tratará esta posibilidad desde el procedimiento que diseña nuestra Ley Concursal y su contribución en lo que podríamos denominar como una incipiente «Responsabilidad Social Concursal».

* La elaboración de la presente comunicación se inserta en el marco del Proyecto de Investigación DER 2010-18660, «Crisis económica y Derecho Mercantil», dirigido por el Profesor D. José Miguel Embid Irujo. 
Palabras clave: Concurso, cooperativas, conservación de PYMES, recuperación de PYMES, «Responsabilidad Social Concursal».

Abstract: The fact that lawmakers design measures for restructuring and putting businesses on sound footing without taking SMEs into account is a source of great concern in a country like Spain whose industrial fabric is formed by a much larger number of SMEs than in other countries. Even medium sized companies end up «dying in the long term» due to insolvency procedures which drive them to unavoidable settlements. In view of this problem which lawmakers have not solved and a neverending economic crisis, cooperatives are called to take an active role as the main players in restructuring and recovering businesses. We have gained valuable experience through our past industrial reorganisation and that of other countries such as Argentina where the recession led to spontaneous social phenomena in which workers staged an economic resistance movement known as the «Movimiento Nacional de Fábricas Recuperadas». This was mostly distinctive for workers themselves managing to buy the bankrupt company's facilities and continue operating as a cooperative. This brief study focuses on this possibility from the procedures set down in our Insolvency Act and its contribution to what we could call an emerging «Social Responsibility in Insolvency».

Key words: Insolvency, cooperatives, safeguard SMEs, recover SMEs, «Social Responsibility in Insolvency». 


\section{Introducción}

Debemos esclarecer desde el inicio de este trabajo que la finalidad del procedimiento concursal es la satisfacción de los acreedores, pero no por ello la Ley Concursal es ajena a las ventajas que tanto para los acreedores como para el resto de intereses afectados por la crisis pueden derivarse de la conservación de la estructura empresarial. Esta orientación conservativa de la empresa, por otra parte presente en mayor o menor medida en la actualidad en el conjunto del Derecho concursal comparado ${ }^{1}$ se refleja en medidas de conservación ${ }^{2}$ previstas en la fase común del concurso y de las que en última instancia depende la posibilidad de conservación, ya sea a través de un convenio de continuación o de una enajenación en bloque, de los que hablaremos, así como del régimen jurídico del convenio, dedicándose especial atención a la «propuesta anticipada de convenio», como medio de facilitar y anticipar el arreglo negociado. Exponente de esta moderna tendencia lo encontramos en la reciente reforma publicada el 1 de marzo de $2012^{3}$ que ha experimentado el régimen concursal alemán que ha pasado recientemente por cambios significativos a través del "Gesetz zur weiteren Erleichterung der Sanierung von Unternehmen» (conocida como ESUG, también como (InsOuaÄndG) - Ley para facilitar el saneamiento de las empresas-) y que modifica aspectos esenciales de la Insolvenzordnung de 5 de octubre de 1994. Según el Ministerio de Justicia alemán, la ley proporciona la base para una nueva cultura de los procedimientos de in-

1 Esta situación es diferente, en los países de nuestro entorno. De este modo nos advierte Largo Gil. R. («El convenio concursal mediante la modificación estructural de la sociedad concursada (algunas consideraciones a los cuatro años de la entrada en vigor de la ley concursal)», en Revista de Derecho Concursal y Paraconcursal, n. ${ }^{\circ}$, Sección Estudios, segundo semestre de 2008, p. 87) que «es un movimiento promovido desde instancias comunitarias y del que es representativa la Ordenanza sobre la insolvencia alemana (Insolvenzordnung) de 5 de octubre de 1994, en la que se abre la posibilidad de recuperar - conservar - a las empresas que tengan posibilidades de recuperación. En realidad, se trata de un derecho preventivo de las crisis con medidas adecuadas para impedir situaciones irreversibles. A este respecto, hay que poner de relieve la generalización en los últimos años de las reformas de la legislación concursal en algunos países de la Unión Europea en vistas a la recuperación de empresas en crisis, siendo Portugal, Francia e Italia las más recientes dentro del movimiento referido».

2 Sobre las mismas, vid. Zabaleta Díaz, Marta, El principio de conservación de la empresa en la Ley Concursal, Madrid, 2006.

3 G. v. 07.12.2011 BGBI. I S. 2582 (Nr. 64), 2800; Geltung ab 01.03.2012. 
solvencia, que se enfoca en la supervivencia de la empresa y no en su liquidación ${ }^{4}$.

La crisis económica, como decíamos, ha tenido como consecuencia unos elevados niveles de destrucción de empleo en todo tipo de empresas y sin distinguir su tamaño. En un país como España cuyo tejido empresarial se compone de PYMES en niveles muy superiores al de otros países, llama la atención como las medidas de reestructuración empresarial y saneamiento nunca son diseñadas por el legislador pensando en las PYMES, al contrario, incluso las de tamaño medio acaban «muriendo a lo largo» del procedimiento concursal, abocándas a una irremediable liquidación ${ }^{5}$. Parece, pues, que el interés en «reflotar empresas» se centra en aquellas que por su tamaño «no se les puede de-

4 http://dipbt.bundestag.de/extrakt/ba/WP17/338/33871.html. Los cambios podemos resumirlos en tres puntos: En primer lugar, la autonomía de los acreedores se fortalece a través de la creación de un comité de acreedores ya desde el inicio del concurso. En segundo lugar, los derechos del deudor dispuesto a sanear se refuerzan mediante un procedimiento de protección: En un período de tres meses, el deudor puede elaborar un plan de saneamiento que se implementará como plan de insolvencia. Este procedimiento protege al deudor, no sólo contra las medidas de ejecución, sino también contra la pérdida capacidad dispositiva. El tercer punto es la ampliación del proceso del plan de insolvencia. En particular, la conversión de deudas en acciones («debt-equity-swap») es una nueva característica.

5 Es relevante a estos efectos el estudio estadístico «Estadística concursal», en Anuario 2011, realizado Van Hemmen, E., editado por Colegio de Registradores de la Propiedad, Bienes Muebles y Mercantiles de España, Madrid, 2012., en el que se señala que para valorar si el nivel de recursos generados de las concursadas les permitirá sobrevivir al procedimiento, debemos tener en cuenta que el hecho de que en 2011 solamente el $11 \%$ de las empresas exhiba una capacidad suficiente para liquidar sus deudas en menos de 10 años resulta muy revelador, ya que son 5 los años que establece la Ley Concursal (art. 100.1) como límite normal para las esperas de los convenios (siendo la "espera» el período de tiempo total para el que se programan los compromisos de pago futuros), lo que, unido a que la quita normalmente no puede superar el 50\%, nos Ileva a concluir que solamente este $11 \%$ tiene potencial para alcanzar un convenio. No mejoran, por tanto, las expectativas de supervivencia de las sociedades concursadas del ejercicio 2011 respecto a años anteriores (p. 19) y añade en su p. 46. que una de las características que mejor define a las concursadas que eluden la liquidación es la capacidad para generar recursos. Este resultado se confirma tanto para la sub-muestra de sociedades que presentaron cuentas de acuerdo al PGC 1990 (que entraron mayoritariamente en concurso en 2009), como las que lo hicieron siguiendo los criterios del PGC 2007 (la mayoría de las cuales inició el concurso en 2010). También se confirma que las que inician la fase de convenio, así como las que finalmente logran el acuerdo en 2011 registran mayores volúmenes de tamaño, especialmente si se consideran las que iniciaron el concurso en 2009. También se observa que para tener posibilidades de sobrevivir al procedimiento, además de poseer una mínima dimensión, la concursada debe acumular experiencia en el mercado: las sociedades que alcanzan el convenio tienen más edad que las que se liquidan (4 años más, si consideramos las medianas). 
jar liquidar», sin pensar en la sangría de puestos de trabajos que supone la suma total de PYMES liquidadas. Ante esta situación, como en otras crisis, las sociedades cooperativas están llamadas a desarrollar un papel activo como protagonistas de procesos de reestructuración y recuperación empresarial de PYMES (pensamos que estos conceptos no deben ser antagónicos). No cabe duda que si esta crisis profunda se alarga, sobre un aumento de concursos gravitará la presión de un regreso a las fórmulas empresariales de autoempleo, con cooperativas, lo cual tiene un perfecto encaje en nuestro modelo constitucional económico ${ }^{6}$.

En este sentido, contamos con la experiencia de nuestra ya vieja reconversión industrial de la década de los años ochenta y con la de países, como la República de Argentina, donde la recesión dio lugar al nacimiento de fenómenos sociales espontáneos en los que los trabajadores han protagonizado un movimiento de resistencia económica «apolítico» y «asindical», conocido como «Movimiento Nacional de Fábricas Recuperadas» caracterizado en la mayoría de las ocasiones, por ser los trabajadores quienes lograron comprar las instalaciones de la empresa concursada y continuaron la explotación a través de una sociedad cooperativa ${ }^{7}$. En el presente trabajo se examinará esta posibilidad desde el procedimiento que arbitra nuestra Ley Concursal (en adelante LC), en su fase de convenio, examinando los llamados «convenio de continuación», sin que por ello se descarte la posibilidad que prevé la LC en fase de liquidación de enajenación de la empresa como un todo - con el objeto de no destruir esa unidad de producción de bienes y servicios cumpliendo con la finalidad conservativa o continuadora de la empresa-, o formando parte de un acuerdo de refinanciación en fase preconcursal (aunque este solo esté pensado para empresas de un tamaño grande o medio). No obstante, por razones de extensión de este trabajo nos remitimos a posteriores trabajos en curso.

6 Sobre estas cuestiones, vid. nuestro trabajo, Pastor Sempere, C., «Empresa cooperativa y modelo constitucional económico: una aproximación», en Revista de Sociedades de la Editorial Aranzadi, número 16, 2001, pp. 191-215.

7 Gils Carbó, A.M., «Fábricas recuperadas en Argentina mediante cooperativas de trabajadores en los procesos de quiebra», en AA.VV., Derecho de Sociedades y concurso. Cuestiones de actualidad en un entorno de crisis. Dir. Embid Irujo, J.M./León Sanz, F.J., pp. 597-609, Granada 2011. En la actualidad, en Argentina, la ley 26.684 de Concursos y Quiebras (publicada en el Boletín Oficial de 3 de junio de 2011) —que modifica la anterior Ley 24.522 - entre sus principales reformas, habilita la participación activa de los trabajadores en un proceso de quiebra y da prioridad de adquisición de una empresa cerrada a sus trabajadores agrupados en una cooperativa. 


\section{Finalidad del procedimiento concursal}

No obstante lo señalado en nuestras consideraciones introductorias, el procedimiento que arbitra la LC no se decanta claramente hacia la continuación de la actividad, a pesar de que se deduce que el convenio se concibe como la solución normal del concurso, en beneficio de los acreedores, del concursado, de los trabajadores y de otros intereses (exposición de motivos apart. IV de la LC de 2003) 8.

Asimismo, la apertura de la fase de liquidación en la LC no es incompatible, insistimos, con la finalidad conservativa o continuadora de la empresa, ya que en la fase de liquidación se prevé la posibilidad de enajenación de la empresa como un todo ${ }^{9}$, con el objeto de no des-

8 En referencia a la finalidad del con concurso con carácter general, entre otros, el profesor Olivencia, en su intervención ante la Comisión de Justicia del Congreso de los Diputados (en su comparecencia en el Congreso de los Diputados, publicada en el Boletín Oficial de las Cortes Generales de 29 de octubre de 2002, núm. 604), en su condición de Presidente de la Sección Especial para la Reforma Concursal de la Comisión General de Codificación, en la que afirmo «La finalidad del Proyecto no es la reestructuración de empresas, no es la de un saneamiento a ultranza de empresas..... lo que hay es el respeto a un principio de conservación de la empresa que es algo distinto de reestructuración». Debemos recordar en este punto, que el apartado VI de la Exposición de Motivos de la Ley señala que el convenio, como solución normal del concurso, tiende a alcanzar la satisfacción de los acreedores. Indica Pulgar Ezquerra («El Proyecto de Ley de medidas de lucha contra la morosidad en las operaciones comerciales y la nueva legislación comercial», en Actualidad Jurídica Aranzadi, n. ${ }^{\circ}$ 604/2003) que aunque falta en la LC una declaración programática sobre los fines del concurso, en ella no se atribuyen "finalidades quirúrgicosanitarias a los procedimientos concursales», ya que «el concurso persigue prioritariamente la satisfacción de los acreedores preferentemente a través de la conservación de empresas y no tanto al saneamiento» de éstas, aunque el convenio «pueda, en ocasiones, cumplir una función sanatoria». En referencia a este mismo apartado de la citada Exposición de Motivos señala De la Cuesta Rute (El convenio concursal, comentario a los artículos 98 a 141, Madrid, 2004, pp. 16 y 17) «se alude a la finalidad del convenio de conservar la actividad profesional o empresarial del concursado pero en modo alguno determinante del convenio y como algo instrumental para la finalidad solutoria de éste, que no excluye sin embargo que además el convenio reporte provecho o utilidad a otros intereses de los acreedores. Terminantemente la Exposición de Motivos señala que el objeto del concurso no es el saneamiento de empresas». Por último para Font Galán/Miranda Serrano/Pagador LópezNela Torres, "Viabilidad antitrust de las soluciones concursales de conservación de la empresa, socialización concursal del Derecho de la Competencia», RDM, n. ${ }^{\circ} 250,2003$, p. 475. "aunque la Ley no lo diga de modo expreso, el concurso no está reñido con la finalidad conservativa o continuadora de la empresa».

9 Vid. Rubio Vicente, "efectos jurídicos de la enajenación de la empresa del concursado», en Revista de Derecho Concursal y Paraconcursal, n. ${ }^{\circ}$ 1, 2004, pp. 259 a 274.; y del mismo autor «la enajenación de la Empresa en la nueva Ley Concursal», en Revista de Derecho de Sociedades, 2004; Vilata Menadas, S., «El tratamiento de la sucesión 
truir esa unidad de producción de bienes y servicios ${ }^{10}$. Lo señalado, nos lleva a adelantar una hipótesis; y es que aunque parezca contradictorio puede resultar más sencillo la continuidad y asunción por parte de los trabajadores de la empresa o de la unidad productiva en el marco de la fase de liquidación, que lograr un convenio de continuidad con los acreedores de la concursada. En cualquier caso, a continuación nos vamos a detener en el instrumento «elegido» por la Ley que es el convenio y el contenido pensado por el legislador para dar soporte a la necesidad apuntada en nuestra introducción.

\section{Fase de convenio: especial referencia a los convenios de «continuación»}

El Convenio es un acuerdo entre el deudor y la colectividad de sus acreedores, aprobado por el juez y que tiene como objetivo primordial

empresarial en el traspaso de unidades empresariales: una visión jurisprudencial», en Revista de Derecho Concursal y Paraconcursal, n. ${ }^{\circ} 8$, Sección Comunicaciones, Primer semestre de 2008, p. 491; Herrera Cuevas, E., "La reorganización traslativa en concurso y sucesión de empresa», Revista de Derecho Concursal y Paraconcursal, n. ${ }^{\circ}$ 9, Sección Varia, segundo semestre de 2008, p. 147. Zabaleta Díaz, Marta, El principio de conservacion de la empresa en la ley concursal, Madrid, 2006; Hualde López, I., La Fase de liquidación en el proceso concursal, Cizur Menor, 2008, pp. 19 y ss.

10 El profesor Olivencia, en su intervención ante la Comisión de Justicia del Congreso de los Diputados (en su comparecencia en el Congreso de los Diputados, publicada en el Boletín Oficial de las Cortes Generales de 29 de octubre de 2002, núm. 604), señaló como manifestación del principio de conservación de la empresa el supuesto en la fase de liquidación de la enajenación de la empresa como un todo, con el objeto de no destruir esa unidad de producción de bienes y servicios. Incluso, como han señalado Font Galán/Miranda Serrano/Pagador López/Vela Torres ( Viabilidad antitrust de las soluciones concursales....», op. cit., p. 475) «por no decir -abiertamente- que la Ley no disimula su predilección porque, cualquiera que sea la solución del concurso no se ve afectada, en la medida de lo razonable, la unidad, existencia y continuidad de la empresa» de este modo, en la fase de liquidación, ordena que el plan de liquidación «siempre que sea factible, deberá contemplar la enajenación unitaria del conjunto de los establecimientos, explotaciones y cualesquiera otras unidades productivas de bienes y servicios del concursado o de alguno de ellos». Esto mismo queda reflejado en las reglas supletorias para el caso de no aprobación del Plan o de remisión de este a las citadas reglas. intervención Para Muñoz Cadenas («Reflexiones en torno a las cesiones de bienes en los convenios concursales mercantiles», en La Ley, n. ${ }^{\circ} 6070,27$ de julio de 2004 , p. 5), en referencia a los citados artículos señala que aun en el supuesto más extremo cual es la liquidación, se ordena como principio general la enajenación de las unidades productivas como un todo, añadiendo que esta regla que se establece como supletoria, a buen seguro regirá como norma de observancia general, a menos que el plan apruebe otra forma de liquidación de las unidades productivas porque así lo aconsejen las circunstancias del concurso, y todo ello, claro está, bajo supervisión judicial. 
la satisfacción de los acreedores. El convenio es un pacto entre el deudor y sus acreedores con una finalidad solutoria, pero que al adoptarse en un procedimiento concursal adquiere una dimensión pública y se somete a un importante control judicial. Ciertamente el convenio puede ser en algunos casos, no en todos, una solución mejor a la liquidación, pero lo que no admite la ley es que por esta vía, que comporta importantes sacrificios y renuncias para los acreedores, se impongan condiciones que impliquen, de facto, una pérdida de su derecho de cobro.

Ello es así porque el convenio es, ante todo, un instrumento solutorio dirigido a satisfacer los intereses de los acreedores, siendo la conservación de la empresa o de la actividad una finalidad instrumental del mismo. Se ha insistido mucho en que la continuación de la actividad de la empresa es un fin de la Ley concursal, aspecto que aun siendo cierto debe ser matizado, pues no es un fin en sí mismo - ya que el objeto del concurso es lograr un pago ordenado a los acreedores - sino un fin ligado a lo que es el objeto del proceso concursal y solo es válido si sirve para ello y, en caso de vinculación al convenio, si no desnaturaliza su carácter solutorio.

El convenio es, por tanto, y, ante todo, un medio de cumplimiento de las obligaciones del deudor, quedando vigente, en lo no modificado por la Ley concursal, lo dispuesto en los artículos 1156 y siguientes del Código Civil y, en concreto lo relativo a la identidad de la prestación. De este modo, y siguiendo el Auto JM-7 Madrid 23.07.2008 (Concurso FORUM FILATÉLICO, S.A.,209/2006), el artículo 1166 del citado texto legal establece que el deudor de una cosa no puede obligar a su acreedor a que reciba otra equivalente o diferente, aunque fuera de igual o mayor valor que la debida. Es decir, si el deudor debe entregar una suma de dinero el acreedor no puede ser compelido por mor de la eficacia del convenio a percibir una cosa distinta si no lo desea, STS de 2 de noviembre de 1994 y 17 de diciembre de 2003, entre otras.

Al respecto, las modificaciones llevadas a cabo por la última reforma de la LC en octubre de 2011 —mediante el RD 38/2011, de 10 de octubre-, no ha introducido sustanciales cambios sobre el contenido del convenio, por lo que siguen manteniendo su vigencia las consideraciones realizadas tanto por la doctrina como por la jurisprudencia. En realidad, dicha reforma ha realizado pequeñas mejoras técnicas a la redacción del artículo 100.2 junto con la del 102.1 y ahora cuando ambos preceptos se refieren a las propuestas alternativas dicen «propuestas alternativas para todos o algunos de los acreedores», dejando claro que no tienen que dirigirse necesariamente sólo a «clases»de acreedores, sino a todos o algunos de ellos. También se ha mejorado al dar ca- 
bida a las propuestas de convenios anticipados y las propuestas condicionadas de concursos conexos del art. 101.2. Se sigue manteniendo la prohibición de pacto de cesión de bienes o derechos a los acreedores a salvo, ahora, del supuesto recogido en el artículo 155.4 de la LC -acreedor con privilegio especial-. Así, pues, el artículo 100.1 de la Ley concursal indica que toda propuesta de convenio deberá incluir propuesta de quita o espera o combinar ambas, pues estos son los únicos modos de reorganización del pasivo del deudor a los que puede compelerse al acreedor por la eficacia del convenio en los términos del artículo 136 de la Ley concursal, cualquier otra modalidad alternativa de cumplimiento debe ser aceptada expresa o tácitamente por el acreedor en los términos de la Ley concursal. Precisamente el uso de la formula condicional podrá contener, junto al adverbio además en el apartado 2 del artículo 100 de la Ley concursal anterior a la reforma de octubre de 2011 — «la propuesta de convenio podrá contener, además, proposiciones alternativas para todos los acreedores o para los de una o varias clases, incluidas las ofertas de conversión del crédito en acciones, o en créditos participativos»-, evidenciaba que el contenido de las proposiciones alternativas no puede ser el único contenido del convenio, que deberá respetar como propuesta general la identidad de la prestación pactada ${ }^{11}$.

En efecto, esta interpretación ya fue expuesta por la doctrina ${ }^{12}$ que determinó que mediante la conversión del crédito en acciones,

11 Auto JM-7 Madrid 23.07.2008 (Concurso Fórum Filatélico, S.A., 209/2006), la segunda opción, para los ordinarios, mediante capitalización del crédito, adquiriendo acciones de Fórum Filatélico, S.L. De este modo, los acreedores, además de ver reducido su crédito en un $50 \%$ y aplazado hasta cinco años, no perciben su importe en metálico, sino que se ven obligados, en todo caso, a recibir participaciones o acciones lo que infringe los artículos 100, 125 de la Ley Concursal y 1.166 del Código Civil. Esta operación, que es una dación en pago, solo sería válida si consiente expresamente el acreedor, pero en el convenio no se prevé tal circunstancia imponiéndose, en todo caso, como consecuencia de su aprobación. Sin embargo, como se vio el fundamento jurídico primero, la eficacia del convenio solo puede extenderse de modo obligatorio a las quitas y esperas pactadas, pero no a la modificación del objeto de la prestación, que si bien puede contemplarse como alternativa, debe ser expresamente aceptada por el acreedor afectado. Vid. el comentario, en Gutiérrez Gilsanz, A., «El consentimiento en el convenio mediante conversión de créditos en acciones, participaciones o cuotas sociales» (Consideraciones en torno al auto del Juzgado de lo Mercantil núm. 7 de Madrid, de 23 de julio de 2008, de inadmisión a trámite de la propuesta de convenio presentada por Fórum Filatélico S.A.), en Revista de Derecho Concursal y Paraconcursal, n. ${ }^{\circ} 10$, Sección Comentarios y Reseñas de Jurisprudencia, Primer semestre de 2009, p. 279.

12 Flores Doña, M. ${ }^{a}$ S., «Comentario al artículo $100 »$, en Comentarios a la legislación Concursal, t. I. Dir. Pulgar Ezquerra, J./Alonso Ledesma, C./Alonso Ureba, A./Alcover Garau, G., Madrid, 2004, p. 1012. 
participaciones o cuotas sociales (también denominada «capitalización de deuda»), se articula un cambio de la «de objeto de la prestación debida», con lo que desde la perspectiva del Derecho de obligaciones estaríamos frente una dación en pago. Otro tanto cabe decir, en referencia al "crédito participativo» ${ }^{13}$, utilizados en otro tiempo en los procesos de reconversión industrial ${ }^{14}$. Aspecto este que últimamente ha sido modificado en Alemania, entre sus cambios más significativos, a través del "Gesetz zur weiteren Erleichterung der Sanierung von Unternehmen» (ESUG-Ley para facilitar el saneamiento de las empresas) ${ }^{15}$.

De la dicción de la ley Concursal el convenio necesariamente ha de consistir en una quita o una espera que podrán proponerse por separado o cumulativamente, aunque en todo caso con los limites señalados respecto de los créditos ordinarios - límites de espera de 5 años y quita del 50\%, establecidos en el artículo 100.1 LC-.

El primer requisito, de carácter previo, necesario para que una propuesta de convenio desborde los límites de espera de 5 años y quita del 50\%, establecidos en el artículo 100 LC, y pese a ello no infrinja los requisitos de contenido del Convenio establecidos por la Ley, es la de que el Juez autorice la superación de tales limites. Por tanto, solicitada la superación de los mismos, expresamente dado el contenido de la propuesta acompañada, sin olvidar que esta autorización no es au-

13 Sus particularidades han determinado que la doctrina, en su mayoría, destaque que nos encontramos ante un préstamo no enteramente típico, sino que las especialidades solo pueden ser explicadas si se califique a este contrato como mixto, donde sobre la base del préstamo, al que se le añade un pacto parciario, y cuya validez y posibilidad vienen respaldadas por el principio de autonomía de la voluntad del art. 1.255 del Código Civil, vid. García Villaverde, R., "Créditos participativos», en AA.VV., Estudios de Derecho Bancario y Bursátil, homenaje a Evelio Verdera y Tuells. Madrid 1994, pp. 1081 y siguientes, donde el autor realiza un magnífico estudio sobre esta figura., y que es seguido por Fradejas Rueda, O., "Créditos participativos», en AA.VV., Derecho del Mercado Financiero, tomo II, vol. I. Madrid 1994, p. 336.

14 Las primeras referencias que existen en nuestro país de este «préstamo participativo» las encontramos en el Real Decreto-ley 8/1983, de 30 de noviembre, "sobre reconversión y reindustrialización» para las empresas sometidas a dichos procesos, en el que aparece recogida por primera vez esta modalidad, al objeto de poner a disposición de estas empresas nuevas modalidades de financiación que ayudarán a superar las dificultades por las que atravesaban algunas de ellas, en particular las que se encontraban inmersas en procesos de reconversión industrial.

15 La solución despertó muchos recelos y opiniones encontradas sobre la imposición contra su voluntad en forma de acreedores se convirtieran en los «nuevos socios»; Véase las opiniones de los Expertos del Comité Jurídico en http://www.bundestag.de/ bundestag/ausschuesse17/a06/anhoerungen/archiv/12_Sanierung_von_Unternehmen/ 04_Stellungnahmen/index.html. 
tomática, sino que debe concederse «excepcionalmente» por el Juez, cuando, tras realizar un juicio valorativo de la propuesta de convenio, una vez concurran determinados presupuestos, estima oportuno autorizar sobrepasar tales limites, motivadamente. El requisito subjetivo es el de que el concursado sea titular de «empresas cuya actividad pueda tener especial trascendencia para la economía». Aunque la Ley se refiere al "concurso de empresas», es claro que está utilizando este término con un significado subjetivo, esto es, como equivalente a empresario individual o societario. Pero la Ley ni define qué entiende por tener especial trascendencia para la economía, ni enumera, siquiera fuera a título de ejemplo, los casos en los que esa característica concurre, ya que, necesariamente debe ser considerada en función del ámbito, tanto sectorial como geográfico dónde se circunscribe la concursada. Cuestión que no fue resuelta por la reforma de marzo de 2009, - que por el contrario si eliminó el requisito de previo de autorización de la autoridad administrativa económica competente- ni por la de octubre de 2011.

El requisito objetivo consiste en que el plan de viabilidad que acompaña a la solicitud contemple expresamente, como condición objetiva para esa viabilidad, la superación de uno o de ambos límites legales máximos. Para que el juez admita a trámite la propuesta de convenio es condición necesaria la objetiva viabilidad, esto es, que el plan de viabilidad contemple la necesidad de una quita superior a la mitad del importe de cada crédito ordinario o de una espera superior a cinco años, o la necesidad de ambas, para poder cumplir el convenio con los recursos que genere la continuación total o parcial de la actividad profesional o empresarial del deudor. Significa ello que sólo es posible superar esos límites cuando, para atender al cumplimiento del convenio, se prevea contar con los recursos que genere la continuación, total o parcial, de la actividad profesional o empresarial, ya que sólo en este caso procede presentar el denominado plan de viabilidad (art. 100.5). Es indiferente que la continuación de la actividad corra a cargo del propio concursado o que sea un tercero - el asuntor - quien continúe, total o parcialmente, dicha actividad (art. 100.2-II, inciso segundo). La única diferencia radica en que, si la continuación de la actividad corre a cargo, total o parcialmente, de un tercero se exige que, el juez, antes de admitir a trámite la solicitud, oiga a los representantes legales de los trabajadores (art. 10.2-II, inciso tercero).

Además de las proposiciones de quita o espera, o combinación de ambas, la propuesta de convenio puede prever la transmisión de la empresa a un tercero, que asuma las deudas y sustituya al concur- 
sado en su actividad empresarial ${ }^{16}$. Es lo que ha venido denominándose «los convenios de continuación».

Estos convenios de continuación ya conocidos en la normativa anterior, deberán detallar (aunque la ley no lo diga) el plazo y condiciones en que se producirá la enajenación. En el caso de transmisión de partes deberá determinarse en la propuesta las deudas afectas a la unidad productiva en cuestión cuyo compromiso de pago asume según lo previsto en el convenio ${ }^{17}$. Además del plan de pagos si contempla contar con los recursos que genere la continuación total o parcial de la actividad empresarial o profesional se deberá acompañar por un plan de viabilidad. A efectos de obligación de aportar el citado documento resulta indiferente que la continuidad quede en manos del concursado o de un tercero, a través de un convenio de continuación.

16 Art. 100.2: «También podrán incluirse en la propuesta de convenio proposiciones de enajenación, bien del conjunto de bienes y derechos del concursado afectos a su actividad empresarial o profesional o de determinadas unidades productivas a favor de una persona natural o jurídica determinada. Las proposiciones incluirán necesariamente la asunción por el adquirente de la continuidad de la actividad empresarial o profesional propia de las unidades productivas a las que afecte y del pago de los créditos de los acreedores, en los términos expresados en la propuesta de convenio. En estos casos, deberán ser oídos los representantes legales de los trabajadores».

17 En orden a exigir una cierta seriedad a la propuesta de Convenio, ésta deberá presentarse acompañada de un plan de pagos con detalle de los recursos previstos para su cumplimiento, incluidos en su caso, los procedentes de la enajenación de determinados bienes o derechos del concursado art. 100.4. Con el objeto de evitar la presentación de propuestas irrealizables, el plan de pagos se deberá determinar los medios con los que cuenta para cumplir con las obligaciones asumidas en el convenio, con lo que la propuesta presentada deberá acomodarse a los recursos disponibles para realizar los pagos a los acreedores. Estos recursos pueden ser propios del deudor o consistir en los que éste o los acreedores proponentes se comprometan a obtener de terceros. El artículo 100.4 de la Ley Concursal indica que el plan de pagos, que necesariamente ha de acompañar a toda propuesta de convenio, debe especificar «con detalle» los recursos previstos para el cumplimiento del convenio, incluidos los generados por la enajenación de determinados bienes o derechos del deudor. Se comprende por ello, que las propuestas de convenio presentadas en la fase común por los acreedores que, como veremos, pueden presentarse desde que transcurra el plazo de comunicación de créditos — difícilmente pueden ir acompañadas de un plan de pagos realmente fiable-. En consecuencia, se ha de precisar de dónde va a salir concretamente el dinero para pagar a los acreedores, indicando las fuentes de recursos que pueden consistir, según se especifica en el propio precepto, en ingresos de la propia actividad empresarial o profesional del concursado, en productos de la venta de bienes o en financiación supletoria obtenida de tercero o de acreedores (art. 100.5), aunque pudiera consistir en cualquier otro tipo de recursos no especificados en el precepto. Cuando la propuesta contuviera compromisos de pago a cargo de terceros para prestar garantías o financiación, realizar pagos o asumir cualquier otra obligación, deberá ir firmada, además, por los compromitentes o sus representantes con poder suficiente (art. 99). 
Efectivamente, el plan de viabilidad, al igual que ocurre con el plan de pagos, ha de especificar los recursos necesarios para la continuidad de la empresa, así como de donde hayan de obtenerse aquellos recursos, aunque tratándose del plan de viabilidad, se refiere también a los rendimientos que se espera generar con la continuación total o parcial de la empresa. También habrán de incluirse en el plan de viabilidad los recursos que se comprometan a aportar terceros, cuyos créditos podrán ser objeto de un trato privilegiado en el convenio, anticipándose su pago al de los créditos concursales.

En realidad, el plan de viabilidad, no está concebido como una pieza de reorganización industrial, sino que más bien parece responder a la necesidad de una mayor seriedad a la propuesta de pago formulada cuando los recursos previstos pretendan obtenerse con la continuación de la actividad empresarial. Incluso, el incumplimiento de las medidas del plan de viabilidad no es causa de resolución del convenio, salvo que impliquen el incumplimiento del Convenio mismo. Es más la falta de concreción respecto su contenido puede convertirlo en un mero formalismo ${ }^{18}$.

Tras lo expuesto debemos realizar algunas observaciones críticas.

En efecto, el principio de conservación de la empresa no constituye un objetivo en sí mismo, sino ante todo un medio para la satisfacción de los acreedores, es básicamente un Convenio solutorio. En lógica coherencia, la inserción del convenio de continuación en el sistema, obliga a continuar pero no a la restructuración y recuperación de la empresa concursa. El compromiso - del asuntor - no alcanza esto último, aunque naturalmente necesitará arreglar el pasivo, el restablecimiento del equilibrio y saneamiento financiero-patrimonial de la empresa no es el objeto de la Ley. Ahora bien, la jurisprudencia ha interpretado la continuidad como sinónimo de actividad. De este modo, si el convenio

18 Sentencia JM-1 Murcia 30.01.2007 (Incidente Concursal 388/2006), «en el plan de viabilidad (condición SEGUNDA del convenio propuesto) se concreta que los recursos que se pretenden obtener para posibilitar la continuación de la empresa procederán de las enajenaciones de los bienes que resulten precisos para tal finalidad, fiscalizadas tales ventas, por la administración concursal. Por tanto, si bien es cierto que el plan de viabilidad, como ocurre con el plan de pagos, no tiene una redacción tan detallada como sería de desear, al especificarse que los recursos precisos para atender uno y otro han de obtenerse en todo caso con la fiscalización, por parte de la administración concursal, de las enajenaciones que sean precisas para ello, se entiende que sendos documentos (plan de pagos y de viabilidad) cumplen con las mínimas exigencias de contenido de los apartados 4 y 5 del art. 100 de la Ley Concursal, pues los administradores en tal caso y pese al cese de su cargo a que alude el segundo inciso del apartado 2 del artículo 133 de la ley Concursal, mantendrían aquella función encomendada en el convenio según les faculta el mismo precepto.» 
trata de trasmitir una empresa en marcha para que sigua funcionando, así Auto JM-1 Málaga 09.07.2008 (Concurso 3031/2006):

Por último la situación del convenio propuesto no tiene viabilidad alguna en relación a la actividad de la sociedad en tanto nada se dice de esta y deja de ser operativo el convenio al respecto de la misma, permitiendo subsistir en el mercado sin actividad, tal y como obra en autos, y sin posibilidad de reactivación, sólo y exclusivamente porque un tercero se compromete al pago de las deudas al $80 \%$ lo que supone defraudar el sistema perseguido por la ley concursal de liquidación ordenada o reordenación de la sociedad según el resultado y convirtiéndose en un medio en el que el administrador de la sociedad se compromete al pago de las deudas societarias, novando subjetiva y objetivamente las mismas, pero reduciendo a través de dicha institución la cuantía de las mismas.

No obstante, lo señalado no evita que quede en evidencia la defectuosa regulación, ya que nuestra LC no determina cuánto tiempo alcanza el compromiso de asunción y continuación con la actividad. La ley guarda, además, silencio sobre dos importantes cuestiones: 1) si las acciones de reintegración de la masa que pudieran subsistir deben considerarse cedidas junto la empresa. 2) en referencia a la asunción del pasivo, no se precisa si el adquirente responde o no de los créditos no reconocidos ${ }^{19}$.

Un hecho destacable es que el actual texto de la LC, no excluye que el adquirente sea un acreedor (también deberá firmar la propuesta (art. 99) ${ }^{20}$. Para la doctrina, este hecho debe ser interpretado conjunta-

19 Pulgar Ezquerra, J. interpreta el silencio que solo se producirá una cesión automática respecto de los créditos insinuados y, respecto de los no insinuados, solo y exclusivamente si el adquirente así los acepta. Con respecto de las acciones de reintegración, en términos generales, entiende la citada autora que deben considerarse cedidas. «Comentario al artículo 100», en Comentarios a la legislación concursal, t. I. Dir. Pulgar Ezquerra, J./Alonso Ledesma, C./Alonso Ureba, A./Alcover Garau, G., Madrid, 2004, pp. 1020 y 1021.

20 Art. 99 se formulará por escrito y firmada por el deudor o, en su caso, por todos los acreedores proponentes, o por sus respectivos representantes con poder suficiente. De las propuestas presentadas se dará traslado a las partes personadas. Cuando la propuesta contuviera compromisos de pago a cargo de terceros para prestar garantías o financiación, realizar pagos o asumir cualquier otra obligación, deberá ir firmada, además, por los compromitentes o sus representantes con poder suficiente. «3. Por lo que respecta a la necesidad de que el proponente —o su representante con poder suficiente- suscriba la propuesta acreditando la legitimación de la firma (artículo 99 LC), debe entenderse por cumplido tal requisito al haber sido plasmada la propuesta en instrumento público»: Auto JM-1 Madrid 16.11.2005 (AC 2005\2067). 
mente con el artículo 103 de la LC dónde se prohíbe la cesión de bienes en pago o para pago de los acreedores, o cualquier forma de liquidación global del patrimonio del concursado, pero no así la venta de la empresa o de determinadas unidades productivas ${ }^{21}$. Tampoco existe cesión liquidatoria en la transmisión patrimonial en el marco de las operaciones societarias de fusión o escisión ${ }^{22}$, en la medida en que salvaguardan tanta la continuidad de la sociedad fusionada, escindida ${ }^{23}$ y ahora, tras la reforma de octubre de 2011 del artículo 100.324, mediante cesión global de activo y pasivo 25 .

Dejando ahora de lado que el art. 100.3 LC ha prohibido los convenios «liquidativos», que eran las formas más habituales de dar por arregladas las suspensiones de pagos en España ${ }^{26}$, conforme al pre-

21 Vid. Hualde López, I., La fase de liquidación en el proceso concursal, Cizur Menor, 2008, pp. 306 y ss.

22 Vid. Beltrán Sánchez, E., "Modificaciones estructurales y concurso de acreedores», en AA.WV., Derecho de Sociedades y concurso. Cuestiones de actualidad en un entorno de crisis. Dir. Embid Irujo, J.M./León Sanz, F.J., pp. 597-609, Granada 2011; Largo Gil, R., «El convenio concursal mediante la modificación estructural de la sociedad concursada (algunas consideraciones a los cuatro años de la entrada en vigor de la ley concursal)», Revista de Derecho Concursal y Paraconcursal, n. ${ }^{\circ}$ 9, Sección Estudios, Segundo semestre de 2008;

23 Vid. in extenso, Largo Gil, R., «El convenio concursal mediante la modificación estructural de la sociedad concursada (algunas consideraciones a los cuatro años de la entrada en vigor de la ley concursal)», Revista de Derecho Concursal y Paraconcursal, n. ${ }^{\circ}$ 9, Sección Estudios, Segundo semestre de 2008, p. 87.

24 Tras la reforma, vid. in extenso, Aranguren Urriza, F.J., "Modificaciones estructurales y concurso de acreedores tras la reforma de la Ley Concursal por la Ley 38/2011, de 10 de octubre de $2011 »$, en AA.VV., Modificaciones estructurales y reestructuración empresarial. Coord. Garrido de Palma, V., Valencia 2011.

25 Nótese cómo el legislador adoptó una posición bastante más clara cuando reformó el régimen jurídico de las denominadas Modificaciones Estructurales de las sociedades de capital a través de la Ley 3/2009 de 3 de abril. En ella la exigencia de unidad económica como eje vertebrador de estas operaciones, deja fuera cualquier duda sobre la apreciación del interés general en la conservación de las empresas (vid., sobre el mismo, Alonso Ureba, A., "La cesión global de activo y pasivo: elementos de caracterización y régimen», en $R d S$ número 33, año 2009-2, especialmente, p. 26; Alonso Ureba, A./Roncero Sánchez, A., "La viabilidad de la aportación de una unidad económica tras la introducción de la segregación por la Ley de Modificaciones Estructurales» en $R d S$, número 34, 2010, especialmente pp. 274 y 275).

26 Vid. las observaciones críticas realizadas por la doctrina en Carrasco Perera, A./ Moratiel Pelletero, E., «Dos paradojas del convenio concursal: eficacia liquidativa y eficacia novatoria», Actualidad Jurídica Aranzadi núm. 614 (Comentario), 2004; igualmente crítica Largo Gil, R., «El convenio concursal mediante la modificación estructural de la sociedad concursada (algunas consideraciones a los cuatro años de la entrada en vigor de la ley concursal)», en Revista de Derecho Concursal y Paraconcursal, op. cit., "la LC prohibe expresamente los convenios de liquidación, frecuentes con el régimen anterior, 
cepto mencionado, queda clara la voluntad del legislador de rechazar todas aquellas propuestas que lleven aparejadas cualquier forma de liquidación global del activo de la concursada, de la transmisión en conjunto de los bienes y derechos que integran la masa activa, es decir, la liquidación como un todo del patrimonio concursal, de los bienes y derechos que conforman el haber destinado a satisfacer al conjunto de los acreedores. Por tanto, en palabras de la profesora J. PULGAR EZQUERRA, «la taxativa prohibición de cláusulas de cesión de bienes en pago o para pago contenida en el art. 103 debe matizarse, pudiendo sostenerse que lo que resultan prohibidas en la Ley son aquellas cesiones de bienes a los acreedores que puedan convertirse en instrumentos de liquidación abordada al margen de la liquidación global, esto es, las que pueden conllevar una despatrimonialización en bloque del deudor, pero no aquellas otras que permiten la subsistencia de la empresa, lo que acontece en todo caso en que la cesión cumple las condiciones exigidas en el art. 100.2, apartado 2 LC, esto es, hay cesión global del activo y del pasivo y compromiso firme y justificado de continuidad empresarial, desapareciendo así todo el riesgo de que la cesión sea liquidativa» 27.

Además, La Ley Concursal, tal y como se expone el Profesor Ángel ROJO ${ }^{28}$, tampoco tutela y admite aquellos convenios de continuación, en los que, en caso de incumplimiento, se atribuya la facultad de enajenar del conjunto de la masa activa para pagar a los acreedores con el producto obtenido de esa liquidación. Si ello se permitiese, estaríamos dando lugar a un fraude de ley, al tratar de justificar una liquidación mediante el abuso de la dicción literal de la normativa. Distinto es el supuesto en que, partiendo de un convenio de continuación, se establezca la enajenación de determinados y concretos bienes del activo concursal, que no afecten de forma global a éste. Aunque en este supuesto deberá hacerse un análisis de la cantidad y entidad de los bienes objeto de enajenación, para apreciar si existe esa liquidación encubierta o no.

en aras de mantener su carácter de solución conservativa y de evitar manipulaciones en perjuicio de algún acreedor. Se ha optado por la limitación del contenido del convenio, por su «moralización» para evitar daño a los acreedores — de unos en beneficio de otros- El legislador se ha excedido en la limitación de la autonomía privada de las partes. Es uno de los factores impeditivos para la adopción de la solución solutoria negocial y conservativa que es el convenio. Ya hay vías en la LC para evitar los riesgos que se trata de atajar».

27 Pulgar Ezquerra, J., «Comentario al artículo 100», en Comentarios a la legislación Concursal, t. I. Dir. Pulgar Ezquerra, J./Alonso Ledesma, C./Alonso Ureba, A./Alcover Garau, G., Madrid, 2004, pp. 1028 y 1032.

28 En la obra «El comentario a la ley concursal». 
En definitiva, tras lo expuesto, queda abierta la posibilidad de un convenio de continuación para facilitar la continuidad de la empresa concursada en manos de sus trabajadores, directivos y demás colectivos interesados en la marcha de la empresa (a los que se les podría dar cabida a través de las distintas figuras que contemplan nuestras leyes como socios de capital) constituidos previamente en sociedad cooperativa o laboral las cuales asumirán el papel de asuntoras y en dicho marco la capitalización de sus créditos y una refinanciación de la deuda que incluso podría venir del propio sector o de algún organismo público. Lo señalado goza de un nuevo incentivo tras la última reforma, al considerar, expresamente, el que los créditos nacidos tras la aprobación del convenio se consideren contra la masa en caso de apertura posterior de la fase de liquidación.

\section{A modo de conclusión}

No podemos cerrar nuestro trabajo sin hacer una breve reflexión, sobre el convulso panorama legislativo concursal desde el que también se trata de hacer frente a la crisis y su dramática cifra de mortaldad de empresas. A pesar de los escasos años de vigencia y de reformas varias de la Ley Concursal, la práctica diaria sigue demostrando que el procedimiento judicial de insolvencia no constituye una herramienta útil de reestructuración, por ser un procedimiento caro, rígido y lento. Ante esta realidad, un número importante de compañías españolas han recurrido en los últimos tiempos a soluciones extrajudiciales, similares a otras comúnmente utilizadas en el Derecho comparado, con las que han intentado enfocarse hacia la viabilidad, superando sus problemas financieros, de liquidez o estructurales y evitando el procedimiento concursal29.

29 En efecto, antes de cumplir los cinco años de vigencia, la Ley Concursal fue reformada, por el Real Decreto-ley 3/2009, de 27 de marzo, de medidas urgentes en materia tributaria, financiera y concursal ante la evolución de la situación económica ( $B O E$ 31 de marzo). La Exposición de Motivos del Decreto-ley justifica la reforma en la circunstancia de que «la vigente ley se dictó en el año 2003 en un entorno económico completamente distinto al actual, y no ha sido hasta que la crisis financiera internacional se ha trasladado a las empresas cuando se ha podido comprobar la inadecuación de algunas de sus previsiones» y señala inmediatamente después la verdadera finalidad principal de la reforma: "Las modificaciones contenidas en el presente Decreto-ley pretenden facilitar la refinanciación de las empresas que puedan atravesar dificultades financieras que no hagan ineludible una situación de insolvencia, además de agilizar los trámites procesales, reducir los costes de la tramitación, y mejorar la posición jurídica de los trabajadores de empresas concursadas que se vean afectados por procedimientos colectivos» 
La saturación de los Juzgados de lo Mercantil, la generalización de los acuerdos de refinanciación y la demostración de que constituyen una más interesante solución a las crisis empresariales, fundamentalmente en términos de conservación de valor, llevaron al Gobierno a promulgar, con carácter extraordinario, un Decreto-ley 3/2009 que tenía entre sus principales objetivos facilitar la reestructuración de las empresas que puedan atravesar dificultades financieras, acudiendo a las refinanciaciones preconcursales de carácter extrajudicial ${ }^{30}$. Adicionalmente, el Gobierno introdujo otras importantes modificaciones en la Ley Concursal para abaratar y simplificar el procedimiento judicial de insolvencia u optimizar sus mecanismos en interés de los acreedores. No obstante, la reforma no quedo exenta de críticas y en palabras de Prof. BELTRÁN ${ }^{31}$, «En lugar de la reflexión, profundidad y equilibrio que aconsejan una reforma global de la legislación concursal, se ha optado por una reforma parcial, apresurada y carente del necesario equilibrio. El Decreto-ley 3/2009 se ha limitado a abordar la cuestión previa del convenio preconcursal desjudicializado, aunque de una forma muy limitada, mediante una regulación - muy sesgada- de los acuerdos de refinanciación. (...) Se favorece la financiación de la empresa en la fase preconcursal; pero no en la fase concursal». Muchas de estas críticas siguen manteniendo su vigencia en la última reforma operada en octubre de 2011 mediante el RD 38/2011, de 10 de octubre ${ }^{32}$.

En efecto, se ha perdido una oportunidad para atender sus carencias $^{33}$. El nuevo gran protagonismo corresponde a la Administración

30 Paradójicamente, estos procesos extrajudiciales de refinanciación de deuda no estaban regulados en nuestra legislación concursal. De hecho, hasta antes de la reforma de 2009 la Ley Concursal suponía un freno a estos procesos, entre otras razones porque los acuerdos de refinanciación podían ser rescindidos en caso de que sobreviniera un procedimiento formal de insolvencia, vid. Pulgar Ezquerra, «la protección de las refinanciaciones de deuda de las solicitudes de concurso necesario: sobreseimiento en los pagos y comunicación ex art. 5.3 LC en el marco del RDL 3/2009», Revista de Derecho Concursal y Paraconcursal, n. ${ }^{\circ} 11$, Segundo semestre de 2009. De la misma autora, en «Estrategias preconcursales y refinanciaciones de deuda: escudos protectores en el marco del RDL 3/2009», en AA.VV., Implicaciones financieras de la Ley Concursal. Dir. Alonso Ureba/Pulgar Ezquerra, La Ley, Madrid, 2009.

31 Beltrán, La reforma -inarmónica - de la Ley Concursal, publicado on line en www.aranzadi/congresodelainsolvencia/pdfs/reforma.doc.

32 Vid. Aranguren Urriza, F.J., «Modificaciones estructurales y concurso de acreedores tras la reforma de la Ley Concursal por la Ley 38/2011, de 10 de octubre de $2011 »$, en AA.WV., Modificaciones estructurales y reestructuración empresarial. Coord. Garrido de Palma, V., Valencia 2011.

33 En el trámite de convalidación parlamentaria del Real Decreto-ley 3/2009, el Ministro de justicia Francisco Caamaño señaló que «la experiencia habida en estos años aconseja iniciar un proceso de reflexión para abordar una reforma de la Ley Concur- 
Concursal, «su profesionalización», pero pasando de puntillas sobre un aspecto fundamental en cuanto a su función; su valoración de la situación patrimonial de la empresa que debería tener un contenido "prospectivo» dirigido a la conservación de la empresa y "su juicio» sobre su saneamiento, salvamento o recuperación de la empresa que, naturalmente, pasaría por un replanteamiento del Informe que realiza la Administración concursal ${ }^{34}$. Lo cierto es que, frente a la expectativa creada, la Ley 38/2011 de 10 de octubre de reforma de la Ley Concursal, se hace merecedora de la crítica principal que se vertió contra la regulación del Real Decreto Ley 3/2009. Sigue sin acometer un necesario cambio en los planteamientos vectores de nuestra Ley Concursal. Es una reforma demasiado tópica que está llamada, al igual que la anterior, a quedarse corta, a ir a remolque de los acontecimientos y no dar la cumplida respuesta que exige la grave situación por la que atravesamos. Quizá, pueda paliarse, en ciertos casos, con el Real Decretoley 5/2012, de 5 de marzo, de mediación en asuntos civiles y mercantiles, máxime si tenemos en cuenta la disposición adicional única de la Ley 38/2011 de 10 de octubre, de reforma de la Ley Concursal, según la cual el Gobierno debía emitir un informe sobre la aplicación de medidas adoptar para la mejora de la situación de las personas físicas y familias en dificultades para satisfacer sus obligaciones, y especialmente las garantizadas con hipoteca, recientemente convalidado por Decreto 35. Incluso algunos autores y expertos han empezado a plantear la po-

sal de mayor calado y alcance», anunciando que se encomendaría a la Comisión General de Codificación «la elaboración de una propuesta de actualización integral de la Ley Concursal».

34 A modo del Insolvezplan alemán. En Alemania, el administrador de la insolvencia («Insolvenzverwalter»), debe esclarecer en su informe la situación económica del deudor y sus causas, si hay perspectivas fundadas de mantener en todo o en parte la empresa, lo que puede terminar en un juicio favorable al saneamiento de la empresa o a su inmediata liquidación (Insolvenzordnung, par. 156, de 5 de octubre de 1994). Por el contrario, en España el informe, debe proporcionar una «imagen estática, poliédrica y actual» de la situación patrimonial de la empresa concursada. Es decir, no se trata de que la administración concursal haga un estudio de viabilidad sobre la continuidad de la empresa, simplemente suministran la información suficiente para que, de esta, los sujetos involucrados en el proceso concursal dispongan de una información adecuada acerca del valor de la empresa en funcionamiento, pero también, y a la vez, sobre el valor de liquidación. Vid. Pastor Sempere, C., "Las cuentas anuales de la sociedad concursada e informe de la administración concursal (art. 75 de la Ley Concursal)», en AA.VV., Gobierno corporativo y crisis empresariales, II Seminario Harvard-Complutense de Derecho Mercantil, Ed. Marcial Pons, Madrid/Barcelona, 2006.

35 El 10 de marzo se publicó en el BOE el Real Decreto-ley 6/2012, «de medidas urgentes de protección de deudores hipotecarios sin recursos». El Real Decreto-ley 27/2012, de medidas urgentes, que entró en vigor el 16 de noviembre no contempla 
sibilidad de recurrir a la medición concursal, en especial, en los supuestos de acuerdos de refinanciación que reúnan los requisitos del artículo 71.6 de la Ley Concursal. Creo que existen razones de peso para descartar esa posibilidad, sobre las que en este trabajo no podemos ahondar, pero lo que sí parece latir en su trasfondo es una preocupación sobre lo que podríamos denominar como incipiente «Responsabilidad Social Concursal».

En definitiva, si realmente queremos que el concurso sea un instrumento al servicio de la recuperación y restructuración de nuestro tejido empresarial, habría que revisar en profundidad, entre otros aspectos, el estatuto del órgano de Administración Concursal y la opción de nuestro legislador por el convenio como solución preferente a la insolvencia, y regular con amplitud, sin reticencias ni cicatería, el contenido y efectos del mismo. Ello en la línea del «procedimiento de reorganización agilizado» sin merma de las garantías para los intereses implicados, en el que expresamente se contemplara el interés de los trabajadores en conservar su puesto de trabajo, recuperando ellos mismos la empresa concursada a través de su explotación mediante un sociedad cooperativa.

\section{Bibliografía}

Alonso Ureba, A./Roncero Sánchez, A.: "La viabilidad de la aportación de una unidad económica tras la introducción de la segregación por la Ley de Modificaciones Estructurales», en Revista de Derecho de Sociedades de la Editorial Aranzadi, número 34, 2010.

Alonso UREBA, A.: "La cesión global de activo y pasivo: elementos de caracterización y régimen», en Revista de Dereceho de Sociedades de la Editorial Aranzadi, número, 33, año 2009-2.

tres de las exigencias que reclamaban las plataformas de afectados por los desahucios. De ahí que su puesta en funcionamiento haya recibido multitud de críticas. Recientemente el jueves 29 de noviembre de 2012 el ministro de Economía y Competitividad, Luis de Guindos (http://www.rtve.es/noticias/dacion-pago/), anunció a finales que en España hay unas 120.000 familias que cumplen todos los requisitos para acogerse a la paralización de desahucios y que las entidades financieras ya se han comprometido a aportar 6.000 viviendas al nuevo Fondo Social de Vivienda que se pondrá en marcha y que está destinado al alquiler con precios bajos para las personas que no tengan hogar. Por su parte, la portavoz parlamentaria del PSOE, Soraya Rodríguez, ha afirmado que el decreto «no paraliza ningún desahucio», sino que solo retrasa dos años la ejecución hipotecaria y que las familias se queden sin casa, acusando al Gobierno de aprobar más bien una moratoria para «evitar tener en el telediario durante dos años situaciones dramáticas de expulsiones» de sus viviendas. 
Aranguren URRIZA, F.J.: «Modificaciones estructurales y concurso de acreedores tras la reforma de la Ley Concursal por la Ley 38/2011, de 10 de octubre de $2011 »$, en AA.VV.: Modificaciones estructurales y reestructuración empresarial. Coord. GARRIDO DE PALMA, V., Valencia 2011.

BeltRÁn SÁnChez, E.: «Modificaciones estructurales y concurso de acreedores», en AA.VV.: Derecho de Sociedades y concurso. Cuestiones de actualidad en un entorno de crisis. Dir. Embid IRUjo, J.M./León SAnz, F.J. Granada 2011

Carrasco Perera, A./Moratiel Pelletero, E.: «Dos paradojas del convenio concursal: eficacia liquidativa y eficacia novatoria», en Actualidad Jurídica Aranzadi, número 614 (Comentario), 2004.

De LA CuestA Rute: El convenio concursal, comentario a los artículos 98 a 141, Madrid, 2004.

Flores DoÑA, M. ${ }^{\text {aS }}$.: "Comentario al artículo 100», en Comentarios a la legislación concursal, t. I. dir. Pulgar Ezquerra, J./Alonso Ledesma, C./Alonso Ureba, A./Alcover Garau, G., Madrid, 2004.

Font Galán/Miranda Serrano/Pagador López/Nela Torres: «Viabilidad antitrust de las soluciones concursales de conservación de la empresa, socialización concursal del Derecho de la Competencia», en Revista de Derecho Mercantil, n. ${ }^{\circ} 250,2003$.

Fradejas Rueda, O.: "Créditos participativos», en AA.VV.: Derecho del Mercado Financiero, tomo II, vol. I. Madrid 1994.

García Villaverde, R.: "Créditos participativos», en AA.VV.: Estudios de Derecho Bancario y Bursátil, Homenaje a Evelio Verdera y Tuells. Madrid 1994.

GILS CARBÓ, A.M.: «Fábricas recuperadas en Argentina mediante cooperativas de trabajadores en los procesos de quiebra», en AA.VV.: Derecho de Sociedades y concurso. Cuestiones de actualidad en un entorno de crisis. Dir. EMBID IRUJo, J.M./LEÓn SANZ, F.J. Granada 2011.

GUTIÉRREZ GILSANZ, A.: «El consentimiento en el convenio mediante conversión de créditos en acciones, participaciones o cuotas sociales» (Consideraciones en torno al auto del Juzgado de lo Mercantil núm. 7 de Madrid, de 23 de julio de 2008, de inadmisión a trámite de la propuesta de convenio presentada por Fórum Filatélico, S.A.), en Revista de Derecho Concursal y Paraconcursal, $n .{ }^{\circ} 10$, Sección Comentarios y Reseñas de Jurisprudencia, primer semestre de 2009.

HeRreRA Cuevas, E.: «La reorganización traslativa en concurso y sucesión de empresa», en Revista de Derecho Concursal y Paraconcursal, n. ${ }^{\circ}$ 9, Sección Varia, segundo semestre de 2008.

HuALDE LÓPEz, I.: La fase de liquidación en el proceso concursal, Cizur Menor, 2008.

LARGO GIL, R.: «El convenio concursal mediante la modificación estructural de la sociedad concursada (algunas consideraciones a los cuatro años de la entrada en vigor de la ley concursal)», en Revista de Derecho Concursal y Paraconcursal, n. ${ }^{\circ}$ 9, Sección Estudios, segundo semestre de 2008.

LARGO GIL, R, «El convenio concursal mediante la modificación estructural de la sociedad concursada (algunas consideraciones a los cuatro años de la en- 
trada en vigor de la ley concursal», en Revista de Derecho Concursal y Paraconcursal, n. ${ }^{\circ}$ 9, Sección Estudios, segundo semestre de 2008.

Muñoz CADENAS: "Reflexiones en torno a las cesiones de bienes en los convenios concursales mercantiles», en La Ley, n. ${ }^{\circ} 6070,27$ de julio de 2004.

PAstor Sempere, C.: «Empresa cooperativa y modelo constitucional económico: una aproximación», en Revista de Derecho de Sociedades de la Editorial Aranzadi, número 16, 2001.

Pastor Sempere, C.: "Las cuentas anuales de la sociedad concursada e informe de la administración concursal (art. 75 de la Ley Concursal)», en AA.VV.: Gobierno corporativo y crisis empresariales, II Seminario Harvard-Complutense de Derecho Mercantil, Ed. Marcial Pons, Madrid/Barcelona, 2006.

Pulgar Ezquerra: «El Proyecto de Ley de medidas de lucha contra la morosidad en las operaciones comerciales y la nueva legislación comercial», en Actualidad Jurídica Aranzadi, n. ${ }^{\circ}$ 604/2003.

Pulgar EzQuerRA: "La protección de las refinanciaciones de deuda de las solicitudes de concurso necesario: sobreseimiento en los pagos y comunicación ex art. 5.3 LC en el marco del RDL 3/2009», en Revista de Derecho Concursal y Paraconcursal, n. ${ }^{\circ} 11$, segundo semestre de 2009.

Pulgar EzQuerRa: "Comentario al artículo 100», en Comentarios a la legislación concursal, t. I. Dir. Pulgar Ezquerra, J./Alonso Ledesma, C./Alonso Ureba, A./ Alcover Garau, G., Madrid, 2004.

Pulgar EZQueRRA: «Estrategias preconcursales y refinanciaciones de deuda: escudos protectores en el marco del RDL 3/2009», en AA.VV.: Implicaciones financieras de la Ley Concursal. Dir. Alonso Ureba/Pulgar Ezquerra, La Ley, Madrid, 2009.

RuBio VICENTE: «Efectos jurídicos de la enajenación de la empresa del concursado», en Revista de Derecho Concursal y Paraconcursal, n. ${ }^{\circ}$ 1, 2004, pp. 259 a 274; y, del mismo autor: "La enajenación de la empresa en la nueva Ley Concursal», en Revista de Derecho de Sociedades, 2004.

VILATA MenadAS, S.: «El tratamiento de la sucesión empresarial en el traspaso de unidades empresariales: una visión jurisprudencial», en Revista de Derecho Concursal y Paraconcursal, n. ${ }^{\circ}$ 8, Sección Comunicaciones, primer semestre de 2008.

Van Hemmen, E.: «Estadística concursal», en Anuario 2011, editado por Colegio de Registradores de la Propiedad, Bienes Muebles y Mercantiles de España, Madrid, 2012.

Zabaleta Díaz, Marta: El principio de conservación de la empresa en la Ley Concursal, Madrid, 2006. 